\title{
Polymorphisms in Toll-like receptor 4 (TLR4) are associated with protection against leprosy
}

\author{
P.-Y. Bochud • D. Sinsimer • A. Aderem • M. R. Siddiqui • \\ P. Saunderson - S. Britton • I. Abraham • A. Tadesse Argaw • \\ M. Janer • T. R. Hawn • G. Kaplan
}

Received: 6 January 2009/Accepted: 31 March 2009/Published online: 9 May 2009

(C) Springer-Verlag 2009

\begin{abstract}
Accumulating evidence suggests that polymorphisms in Toll-like receptors (TLRs) influence the pathogenesis of mycobacterial infections, including leprosy, a disease whose manifestations depend on host immune responses. Polymorphisms in TLR2 are associated with an increased risk of reversal reaction, but not susceptibility to leprosy itself. We examined whether polymorphisms in TLR4 are associated with susceptibility to leprosy in a cohort of 441 Ethiopian leprosy patients and 197 healthy controls. We found that two single nucleotide polymorphisms (SNPs) in TLR4 (896G >A [D299G] and 1196C > T [T399I]) were associated with a protective effect against the
\end{abstract}

P.-Y. Bochud · A. Aderem • M. Janer · T. R. Hawn Institute for Systems Biology,

Seattle, WA, USA

A. Aderem · T. R. Hawn

Department of Medicine, University of Washington,

Seattle, WA, USA

D. Sinsimer · M. R. Siddiqui · G. Kaplan

Laboratory of Mycobacterial Immunity and Pathogenesis,

Public Health Research Institute Center

at the University of Medicine and Dentistry of New Jersey,

Newark, NJ, USA

P. Saunderson

All Africa Leprosy Rehabilitation and Training,

Addis Ababa, Ethiopia

S. Britton · I. Abraham · A. Tadesse Argaw

Armauer Hansen Research Institute,

Addis Ababa, Ethiopia

D. Sinsimer

Graduate School of Biomedical Sciences,

University of Medicine and Dentistry of New Jersey,

Newark, NJ, USA disease. The 896GG, GA and AA genotypes were found in $91.7,7.8$ and $0.5 \%$ of leprosy cases versus $79.9,19.1$ and $1.0 \%$ of controls, respectively (odds ratio $[\mathrm{OR}]=0.34,95 \%$ confidence interval [CI] $0.20-0.57, P<0.001$, additive model). Similarly, the $1196 \mathrm{CC}, \mathrm{CT}$ and TT genotypes were found in $98.1,1.9$ and $0 \%$ of leprosy cases versus $91.8,7.7$ and $0.5 \%$ of controls, respectively ( $\mathrm{OR}=0.16,95 \% \mathrm{CI}$ 0.06--.40, $P<0.001$, dominant model). We found that Mycobacterium leprae stimulation of monocytes partially inhibited their subsequent response to lipopolysaccharide (LPS) stimulation. Our data suggest that TLR4 polymorphisms are associated with susceptibility to leprosy and that

Present Address:

P.-Y. Bochud ( $\square)$

Service of Infectious Diseases, Department of Medicine, Institute of Microbiology, University Hospital and University of Lausanne,

1011 Lausanne, Switzerland

e-mail: Pierre-Yves.Bochud@chuv.ch

Present Address:

M. R. Siddiqui

Centre for Infections, Health Protection Agency,

London, UK

Present Address:

P. Saunderson

American Leprosy Missions,

Greenville, SC, USA

Present Address:

S. Britton

Department of Medicine, Karolinska Institute,

Stockholm, Sweden

Present Address:

A. Tadesse Argaw

Mount Sinai School of Medicine,

New York, NY, USA 
this effect may be mediated at the cellular level by the modulation of TLR4 signalling by M. leprae.

\section{Introduction}

Leprosy remains an important public health concern in developing countries, with an estimated 250,000 new patients each year [1]. Infection with Mycobacterium leprae is characterised by a polarised spectrum of clinical manifestations that correlate with the level and type of cell-mediated immunity $[2,3]$. At one end of the spectrum, tuberculoid leprosy patients have localised lesions that contain few bacilli and a Th1 T-cell-mediated cellular immune response [3-5]. At the opposite end, lepromatous leprosy patients have disseminated infection with extensive lesions containing numerous intra-cellular bacilli and a Th2 T-cell-mediated cellular immune response. This wide range of clinical and immunological presentations makes leprosy a prototypical disease to understand how polymorphisms in innate immunity genes influence adaptive immune responses. Furthermore, insights into leprosy pathogenesis may help elucidate mechanisms of protective immunity to other mycobacteria such as $M$. tuberculosis, a leading cause of morbidity and mortality worldwide.

Toll-like receptors (TLRs) constitute a family of transmembrane proteins that play an important role in initiating the host immune response to various pathogens, including the pathogenesis of mycobacterial infections [6-8]. The interaction of specific mycobacterial agonists with TLRs leads to the production of inflammatory mediators that are critical for the activation of innate and adaptive immune responses $[9,10]$. Among the members of the TLR family, TLR2 (as a heterodimer with TLR1 or TLR6), TLR4 and TLR9 have been shown to interact with mycobacterial agonists [9-11]. A number of studies have established a role for the TLR2-mediated recognition of M. tuberculosis, M. leprae and other non-tuberculous mycobacteria $[10,12]$. In vitro data also supported a role for the TLR4-mediated recognition of an M. tuberculosis ligand that was stimulatory only when isolated from live organisms [13].

For decades, host genetic factors have been known to play an important role in leprosy. Genome-wide studies have identified several loci that are associated with the disease or its clinical presentation (reviewed in $[14,15])$. In addition, studies have reported associations between leprosy and/or leprosy type and polymorphisms in numerous candidate genes, including the tumour necrosis factor $\alpha$ (TNF- $\alpha)$ gene, the interleukin-10 gene, the transporter associated with antigen processing 1 and 2 (TAP1 and TAP2) genes, the natural resistance associated macrophage protein 1 (NRAMP1) gene and the vitamin D receptor gene (reviewed in [14, 16-18]).

Human genetic studies suggest that polymorphisms in TLRs influence susceptibility to a variety of infections $[6,19]$.
We recently demonstrated that a microsatellite polymorphism in TLR2 was significantly associated with the occurrence of reversal reaction among leprosy patients [20]. However, this polymorphism did not strongly influence susceptibility to leprosy itself, nor leprosy type. Therefore, we hypothesised that polymorphisms in TLRs other than TLR2 may influence susceptibility to the disease. Two TLR4 polymorphisms (896G $>$ A [D299G] and 1196C $>$ T [T399I]) are emerging as major variants in TLR genes that influence human susceptibility to a number of infectious diseases, including tuberculosis [21] and invasive aspergillosis [22, 23]. In the present study, we investigated the role of TLR4 polymorphisms in susceptibility to leprosy and its clinical manifestations in an Ethiopian cohort.

\section{Methods}

Human subjects

The enrolment procedures and clinical definitions have been described previously $[20,24]$. Briefly, 441 leprosy patients were drawn from the All Africa Leprosy Rehabilitation and Training (ALERT) Multi-Drug Therapy (MDT) Field Evaluation Study (AMFES) [24] and 197 unrelated, healthy controls were collected from the local population. Selfreported ethnicity included three major ethnic groups (Oromo, Amhara and Gurage). Leprosy types were established on clinical grounds according to the simplified Ridley/ Jopling classification, which adds the rarely occurring borderline borderline (BB) patients to the borderline lepromatous (BL) patients [25]. Twenty-five additional patients were classified as multibacillary (MB) or paucibacillary (PB) according to the WHO classification. Leprosy reactions were reported only in a subgroup of 216 patients and diagnosed as reported elsewhere [26]. Informed consent was obtained from each study participant. The study was approved by human subject review boards from the Armauer Hansen Research Institute (Addis Ababa, Ethiopia), the Rockefeller University (New York, NY), the Public Health Research Institute (Newark, NJ), the University of Washington (Seattle, WA) and the Western Institutional Review Board (Olympia, WA).

DNA sequencing and genotyping

Genomic DNA was extracted from whole blood using standard protocols [20]. To determine whether there were any polymorphisms that are unique to Ethiopians, we sequenced the coding region of 28 individuals ( 9 controls and 19 cases). The polymerase chain reaction (PCR) products were sequenced with Big Dye Terminator v3.0 and analysed on an ABI PRISM 3730 capillary sequencer (Applied Biosystems). Sequences were aligned and ana- 
lysed with the programs PHRED/PHRAP and CONSED [27]. Genotyping among the whole cohort was carried out by the MassARRAYTM technique (Sequenom, San Diego, CA) using a chip-based matrix-assisted laser desorption/ ionisation time-of-flight mass spectrometer as previously described [28]. Single nucleotide polymorphism (SNP) selection included four SNPs, three previously reported SNPs $(896 \mathrm{G}>\mathrm{A}, 1196 \mathrm{C}>\mathrm{T}$ and $1530 \mathrm{G}>\mathrm{T}[\mathrm{Q} 510 \mathrm{H}][6,29])$ and a previously unreported SNP that was discovered by sequencing (1976A $>\mathrm{G}[\mathrm{M} 658 \mathrm{G}])$.

\section{Statistics}

Statistical analyses were performed using Stata 9 (StataCorp, College Station, TX). All SNPs were tested for HardyWeinberg equilibrium using the genhw program. Pairwise linkage disequilibrium was assessed using the pwld program. Haplotypes were inferred separately for each ethnic group using the expectation-maximisation algorithm implemented in the DECIPHER program (S.A.G. E.) [30]. Haplotypes with frequencies $<1.5 \%$ were grouped together. The association of TLR4 SNPs with susceptibility to leprosy and leprosy type was first assessed in a multivariate logistic regression model (general model) that did not assume any particular mode of inheritance and accounted for the presence of each genotype versus the wild type genotype $(0 / 1$ and $1 / 1$, each versus $0 / 0$ ). For statistically significant associations, we performed likelihood ratio tests for three different models versus the general model. Each of these three models assumed one of the following modes of inheritance: dominant (comparing the presence of one or two copies of the minor allele versus no copies), recessive (comparing the presence of two copies of the minor allele versus no or one copies) and additive (no, one or two copies of the minor allele were coded 0,1 and 2, respectively, assuming greater effect with increased copy number of the minor allele). The best fitting model was assumed in the final presentation of the results. The association of TLR4 haplotypes with susceptibility to leprosy was calculated in a logistic regression model including all haplotypes (each coded 0,1 or 2 for the presence of no, one or two copies of the haplotype), using haplotype 1 as a reference. All analyses were adjusted for age groups, sex and ethnicity (when applicable). Since the sample size was limited, especially for rare SNPs, the statistical analyses were initially performed in the whole population. The consistency of significant results was then verified within each ethnic group.

Bacterial strains

M. leprae strain Thai-53 was provided by Dr. James Krahenbuhl of Lousiana State University and was propagated and collected from the mouse footpad model as described previously [31]. M. leprae was irradiated as described previously [31]. Since $M$. leprae grows optimally at 30 $33^{\circ} \mathrm{C}$, which is suboptimal for cell culture, heat-killed $M$. leprae were used as described previously. Heat-killed and viable $M$. leprae were compared previously and were shown to induce similar relative cytokine response from infected monocytes [32, 33, and G. Kaplan, unpublished data].

Human monocyte and peripheral blood mononuclear cell stimulations

Human peripheral blood monocytes and peripheral blood mononuclear cells (PBMCs) were isolated from healthy donors (New Jersey Blood Center, East Orange, NJ) by Ficoll-Paque separation and plated at a density of $3 \times 10^{6}$ PBMCs per well in a 24-well tissue culture plate. For the preparation of monocytes, isolated PBMCs were resuspended in RPMI 1640 and supplemented with $1 \%$ human AB serum (Gemini Bioproducts, Calabasas, CA), allowed to adhere for $2 \mathrm{~h}$ and then washed to remove non-adherent cells. Both adherent monocytes and PBMCs were cultured in RPMI 1640 with $20 \%$ human serum prior to stimulation at a multiplicity of infection (MOI) of 5:1 with heat-killed M. leprae (ML) or stimulation with ultrapure lipopolysaccharide (LPS; $100 \mathrm{ng} / \mathrm{mL}$, InvivoGen, San Diego, CA). Supernatants were collected at $48 \mathrm{~h}$ post-stimulation and analysed by Luminex for the presence of multiple cytokines (Bio-Rad, Hercules, CA).

\section{Results}

The study included 441 leprosy cases and 197 controls (Table 1). The majority of participants were males $(71.6 \%$ of cases and $73.5 \%$ of controls). Self-reported ethnicities were Oromo ( $43.8 \%$ of cases and $46.7 \%$ of controls), Amhara $(28.6 \%$ of cases and $22.3 \%$ of controls) and Gurage $(25.4 \%$ of cases and $25.9 \%$ of controls). Age categories were not equally represented among cases and controls (mean age 39.0 \pm 15.1 years in cases versus $29.1 \pm$ 12.4 years in controls, $P<0.001)$. A total of 298 cases $(68.1 \%)$ were grouped into the lepromatous pole, including 199 borderline lepromatous (BL), 81 lepromatous lepromatous (LL) and 18 multibacillary (MB, WHO classification). Among the 138 cases grouped into the tuberculoid pole (31.9\%), 128 were borderline tuberculoid (BT), three polar tuberculoid (TT) and seven paucibacillary (PB, WHO classification). Among the 441 patients, 216 had complete data on leprosy complications: neuritis occurred in 133 patients $(61.6 \%)$, reversal reaction in 66 $(30.6 \%)$ and erythema nodosum leprosum (ENL) in 17 $(7.9 \%)$. 
Table 1 Baseline characteristics of leprosy cases and control subjects

\begin{tabular}{|c|c|c|c|c|c|}
\hline \multirow[t]{2}{*}{ Characteristics } & \multicolumn{2}{|c|}{ Total leprosy cases } & \multicolumn{2}{|c|}{ Controls } & \multirow[t]{2}{*}{$P$-value ${ }^{\mathrm{a}}$} \\
\hline & $n$ & $(\%)$ & $n$ & $(\%)$ & \\
\hline Number of cases & 441 & $(100.0)$ & 197 & $(100.0)$ & \\
\hline Male gender & 302 & $(71.6)$ & 144 & $(73.5)$ & 0.700 \\
\hline \multicolumn{6}{|l|}{ Ethnicity $^{\mathrm{b}}$} \\
\hline Oromo & 193 & $(43.8)$ & 92 & $(46.7)$ & \multirow[t]{3}{*}{0.337} \\
\hline Amhara & 126 & $(28.6)$ & 44 & $(22.3)$ & \\
\hline Gurage & 112 & $(25.4)$ & 51 & $(25.9)$ & \\
\hline \multicolumn{6}{|l|}{ Age groups } \\
\hline $0-19$ & 41 & $(9.9)$ & 43 & $(22.2)$ & \multirow[t]{4}{*}{$<0.001$} \\
\hline $20-39$ & 159 & $(38.5)$ & 109 & $(56.2)$ & \\
\hline $40-59$ & 168 & $(40.7)$ & 37 & $(19.1)$ & \\
\hline$\geq 60$ & 45 & $(10.9)$ & 5 & $(2.6)$ & \\
\hline \multicolumn{6}{|l|}{ Leprosy type $^{\mathrm{c}}$} \\
\hline Lepromatous lepromatous (LL) & 81 & $(19.7)$ & & & \\
\hline Borderline lepromatous (BL) & 199 & $(48.4)$ & & & \\
\hline Borderline tuberculoid (BT) & 128 & $(31.1)$ & & & \\
\hline Tuberculoid (TT) & 3 & $(0.7)$ & & & \\
\hline \multicolumn{6}{|l|}{ Leprosy complications ${ }^{\mathrm{d}}$} \\
\hline Neuritis & 133 & $(61.6)$ & & & \\
\hline Reversal reaction & 66 & $(30.6)$ & & & \\
\hline Erythema nodosum leprosum & 17 & (7.9) & & & \\
\hline
\end{tabular}

${ }^{a}$ Double-sided Fisher's exact test for the distribution of characteristics among all cases versus controls

${ }^{\mathrm{b}}$ Twenty patients had other ( 5 cases and 9 controls) or missing ( 5 cases and 1 control) ethnicity

${ }^{\mathrm{c}}$ Leprosy type was missing in five patients; 25 patients classified according the WHO as multibacillary (MB, 18 cases) or paucibacillary (PB, 7 cases) are not shown. Borderline borderline patients were classified together with BL (see Methods section). A total of 298 patients were lepromatous $(81 \mathrm{LL}+199 \mathrm{BL}+18 \mathrm{MB})$ and 138 were tuberculoid $(128 \mathrm{BT}+3 \mathrm{TT}+7 \mathrm{~PB}$, see Table 4)

${ }^{\mathrm{d}}$ Complications data were available in 216 patients only

Note that the characteristics of patients and controls have already been reported [20]. They are presented here to provide the reader with an overview of the study population.

The TLR4 SNPs were at Hardy-Weinberg equilibrium and their frequencies were similar among the three ethnic groups, except for $1530 \mathrm{G}>\mathrm{T}$ among Oromo $(P=0.02)$ (Table 2). While both $896 \mathrm{G}>\mathrm{A}$ and $1196 \mathrm{C}>\mathrm{T}$ are in strong linkage disequilibrium among Caucasians (minor allele frequency $\sim 7 \%, R^{2}>0.95$ ), we found that this was not the case in the present study $\left(R^{2}=0.32\right)$ and that 896 A was $\sim 3$ fold less frequent than 1196T, as expected in an African population (Table 3) [34]. To investigate whether polymorphisms in TLR4 were associated with susceptibility to leprosy, we compared the frequencies of TLR4 SNPs among leprosy cases and controls, adjusting for sex, age groups and ethnicity (Table 4). Both TLR4 SNPs 896G>A and $1196 \mathrm{C}>\mathrm{T}$ were less frequent among leprosy cases than controls. The $896 \mathrm{GG}, \mathrm{GA}$ and AA genotypes were found in 91.7, 7.8 and $0.5 \%$ of leprosy cases versus $79.9,19.1$ and $1.0 \%$ of controls, respectively (odds ratio $[\mathrm{OR}]=0.34,95 \%$ confidence interval [CI] $0.20-0.57, P<0.001$, additive model, Table 5). These results were still significant when the three different ethnic groups were analysed separately $(\mathrm{OR}=0.43,95 \%$ CI $0.21-.89, P=0.02$ in Oromo; $\mathrm{OR}=$ $0.34,95 \%$ CI $0.13-0-94, P=0.04$ in Amhara and $\mathrm{OR}=0.18$, $95 \%$ CI $0.05-0.65, P=0.008$ in Gurage). Similarly, the 1196CC, CT and TT genotypes were found in 98.1, 1.9 and $0 \%$ of leprosy cases versus $91.8,7.7$ and $0.5 \%$ of controls, respectively $(\mathrm{OR}=0.16,95 \%$ CI $0.06-0.40, P<0.001$, dominant model, comparing the presence of one or two copies of the minor allele versus no copies). Again, these results were consistent among the three different ethnic groups, although the significance level was not reached in the Gurage population $(P=0.02$ in Oromo; $P=0.04$ in Amhara and $P=0.3$ in Gurage, two-sided Fisher's exact test). A third TLR4 SNP (1530G $>$ T) also tended to be less frequent among leprosy cases than controls $(1530 \mathrm{GG}$, GT and TT genotypes were found in 98.0, 1.8 and $0.0 \%$ of leprosy cases versus 93.6, 5.8 and $0.6 \%$ of controls, respectively, $\mathrm{OR}=0.38,95 \%$ CI $0.14-1.01, P=0.05$, dominant model). However, the assessment of this third SNP 
Table 2 Allelic and haplotypic frequencies of Toll-like receptor 4 (TLR4) single nucleotide polymorphisms (SNPs) in the three Ethiopian populations

\begin{tabular}{|c|c|c|c|c|c|c|c|c|c|}
\hline \multirow[t]{3}{*}{ SNP } & \multirow[t]{3}{*}{ Amino acid change } & \multirow[t]{3}{*}{ rs number } & \multirow{2}{*}{\multicolumn{2}{|c|}{$\frac{\text { Oromo }}{n=285}$}} & \multirow{2}{*}{\multicolumn{2}{|c|}{$\begin{array}{l}\text { Amhara } \\
n=170\end{array}$}} & \multirow{2}{*}{\multicolumn{2}{|c|}{$\begin{array}{l}\text { Gurage } \\
n=163\end{array}$}} & \multirow[t]{3}{*}{$P$-value ${ }^{\mathrm{b}}$} \\
\hline & & & & & & & & & \\
\hline & & & MAF & $\mathrm{HWE}^{\mathrm{a}}$ & MAF & $\mathrm{HWE}^{\mathrm{a}}$ & MAF & $\mathrm{HWE}^{\mathrm{a}}$ & \\
\hline $896 \mathrm{G}>\mathrm{A}$ & D299G & 4986790 & 0.069 & 0.12 & 0.064 & 0.50 & 0.052 & 1.00 & 0.604 \\
\hline $1196 \mathrm{C}>\mathrm{T}$ & T399I & 4986791 & 0.022 & 1.00 & 0.021 & 0.06 & 0.016 & 1.00 & \\
\hline $1530 \mathrm{G}>\mathrm{T}$ & Q510H & 5030719 & 0.030 & 0.02 & 0.010 & 1.00 & 0.007 & 1.00 & \\
\hline $1976 \mathrm{~A}>\mathrm{G}$ & M658G & $\mathrm{N} / \mathrm{A}^{\mathrm{c}}$ & 0.024 & 1.00 & 0.019 & 1.00 & 0.010 & 1.00 & \\
\hline \multicolumn{10}{|l|}{ Haplotype $^{\mathrm{d}}$} \\
\hline 1) ACGA & - & - & 0.907 & - & 0.923 & - & 0.941 & - & \multirow[t]{5}{*}{0.235} \\
\hline 2) GCGA & - & - & 0.024 & - & 0.030 & - & 0.028 & - & \\
\hline 3) GTGA & - & - & 0.020 & - & 0.021 & - & 0.016 & - & \\
\hline 4) $\mathrm{ACGG}$ & - & - & 0.020 & - & 0.015 & - & 0.006 & - & \\
\hline 5) GCTA & - & - & 0.024 & - & 0.009 & - & 0.003 & - & \\
\hline
\end{tabular}

MAF $=$ minor allele frequency; HWE $=$ Hardy-Weinberg equilibrium test

${ }^{\text {a } H a r d y-W e i n b e r g ~ e q u i l i b r i u m ~ w a s ~ c a l c u l a t e d ~ f o r ~ e a c h ~ l o c u s ~ a n d ~ t h e ~} P$-value is reported. A $P$-value of $<0.05$ indicates that the alleles are not in HWE

${ }^{\mathrm{b}}$ Double-sided Fisher's exact test for the overall distribution of alleles/haplotypes among the three ethnic groups

${ }^{\mathrm{c}} \mathrm{SNP} 1976 \mathrm{~A}>\mathrm{G}$ has not been previously reported

${ }^{\mathrm{d}}$ Haplotypes with an MAF $<1.5 \%$ in the whole population are not shown

TLR4 SNPs were not in linkage disequilibrium with any of the TLR2 polymorphisms that have been previously analysed in this population [20]

among the different ethnic groups was limited by the small sample size. In the analyses by haplotypes, all haplotypes that contained the $896 \mathrm{~A}$, the $1196 \mathrm{C}$ and/or the $1530 \mathrm{~T}$ alleles were associated or tended to be associated with protection against leprosy (OR=0.48, 95\% CI $0.21-1.08, P=0.08$ for haplotype $2, \mathrm{OR}=0.12,95 \% \mathrm{CI} 0.05-0.34$ for haplotype 3 and $\mathrm{OR}=0.23,95 \% \mathrm{CI} 0.08-0.69, P=0.008$ for haplotype 5 , compared to haplotype 1 , Table 6). Together, these results suggested that TLR4 polymorphisms are associated with susceptibility to leprosy.

Table 3 Linkage disequilibrium between the TLR4 SNPs in all ethnic groups

\begin{tabular}{lllll}
\hline SNPs & $896 \mathrm{G}>\mathrm{A}$ & $1196 \mathrm{C}>\mathrm{T}$ & $1530 \mathrm{G}>\mathrm{T}$ & $1976 \mathrm{~A}>\mathrm{G}$ \\
\hline $896 \mathrm{G}>\mathrm{A}$ & 0.06 & & & \\
$1196 \mathrm{C}>\mathrm{T}$ & 0.32 & 0.02 & & \\
$1530 \mathrm{G}>\mathrm{T}$ & 0.26 & 0.00 & 0.02 & \\
$1976 \mathrm{~A}>\mathrm{G}$ & 0.00 & 0.00 & 0.00 & 0.02 \\
\hline
\end{tabular}

Pairwise linkage disequilibrium (LD) were calculated with the pwld program developed in Stata 9 (StataCorp, College Station, TX). Off-diagonal elements are estimates of $R^{2}$, assuming HardyWeinberg equilibrium. The diagonal elements are minor allele frequencies (in italics). LD between $896 \mathrm{G}>\mathrm{A}$ and $1196 \mathrm{C}>\mathrm{T}$ was similar among the three ethnic groups $\left(R^{2}=0.34\right.$ in Oromo, $R^{2}=$ 0.32 in Amhara and $R^{2}=0.27$ in Gurage)
Then, we compared frequencies of the TLR4 SNPs among leprosy patients with lepromatous (LL and BL) and tuberculoid (BT and TT) leprosy, adjusting for sex, age groups and ethnicity (Table 4). There was an association at the limit of the significant level between the 1196C $>$ T SNP and lepromatous leprosy. The 1196CC, CT and TT genotypes were found in 98.9, 1.1 and $0 \%$ of lepromatous leprosy patients versus $96.2,3.8$ and $0 \%$ of tuberculoid patients, respectively $(\mathrm{OR}=0.23,95 \%$ CI $0.05-0.99, P=$ 0.05 , dominant model). No significant association was found when lepromatous lepromatous patients were compared with the other leprosy patients. Together, these results suggested that TLR4 SNPs are not strongly associated (if at all) with the type of leprosy.

Next, we investigated whether TLR4 polymorphisms were associated with the occurrence of leprosy complications. No association was found between TLR4 SNPs and neuritis. The $1530 \mathrm{~T}$ allele was more frequent in patients with reversal reaction $(2 / 15[13 \%]$ in patients with reversal reaction versus $3 / 177$ [1.7\%] in those without reversal reaction, $P=0.05$, Fisher's exact test) and ENL (4/58 [6.9\%] in patients with ENL versus 1/133 [0.7\%] in those without ENL, $P=0.03)$. However, the interpretation of these results is limited by the small sample size, which prevented stratification into separate ethnic groups and the use of multivariable models. 
Table 4 Association of TLR4 SNPs with leprosy and leprosy type

\begin{tabular}{|c|c|c|c|c|c|c|c|c|c|c|c|c|c|c|c|}
\hline \multirow[t]{2}{*}{ SNP } & \multicolumn{2}{|c|}{$\begin{array}{l}\text { Leprosy } \\
n=441\end{array}$} & \multicolumn{2}{|c|}{$\begin{array}{l}\text { Controls } \\
n=197\end{array}$} & \multirow[t]{2}{*}{$P$-value } & \multicolumn{2}{|c|}{$\begin{array}{l}\text { Lepromatous, } \\
n=298\end{array}$} & \multicolumn{2}{|c|}{$\begin{array}{l}\text { Tuberculoid, } \\
n=138\end{array}$} & \multirow[t]{2}{*}{$P$-value } & \multicolumn{2}{|c|}{$\begin{array}{l}\text { Lepromatous } \\
\text { Lepromatous, } \\
n=81\end{array}$} & \multicolumn{2}{|c|}{$\begin{array}{l}\text { Other, } \\
n=355\end{array}$} & \multirow[t]{2}{*}{$P$-value } \\
\hline & $n$ & $(\%)$ & $n$ & $(\%)$ & & $n$ & $(\%)$ & $n$ & $(\%)$ & & $n$ & $(\%)$ & $n$ & $(\%)$ & \\
\hline \multicolumn{16}{|c|}{$896 \mathrm{G}>\mathrm{A}$} \\
\hline $\mathrm{G} / \mathrm{G}$ & 375 & (91.7) & 155 & (79.9) & ref. & 256 & (91.8) & 119 & (91.5) & ref. & 73 & (91.3) & 302 & (91.8) & ref. \\
\hline $\mathrm{G} / \mathrm{A}$ & 32 & (7.8) & 37 & (19.1) & $<0.001$ & 22 & (7.9) & 10 & (7.7) & 0.95 & 7 & (8.8) & 25 & (7.6) & 0.86 \\
\hline $\mathrm{A} / \mathrm{A}$ & 2 & $(0.5)$ & 2 & $(1.0)$ & 0.08 & 1 & $(0.4)$ & 1 & $(0.8)$ & - & 0 & $(0.0)$ & 2 & $(0.6)$ & - \\
\hline \multicolumn{16}{|c|}{$1196 \mathrm{~T}>\mathrm{C}$} \\
\hline $\mathrm{T} / \mathrm{T}$ & 407 & $(98.1)$ & 179 & (91.8) & ref. & 282 & (98.9) & 125 & (96.2) & ref. & 78 & (98.7) & 329 & (97.9) & ref. \\
\hline $\mathrm{T} / \mathrm{C}$ & 8 & (1.9) & 15 & (7.7) & $<0.001$ & 3 & $(1.1)$ & 5 & $(3.8)$ & 0.05 & 1 & $(1.3)$ & 7 & $(2.1)$ & 0.58 \\
\hline $\mathrm{C} / \mathrm{C}$ & 0 & $(0.0)$ & 1 & $(0.5)$ & - & 0 & $(0.0)$ & 0 & $(0.0)$ & - & 0 & $(0.0)$ & 0 & $(0.0)$ & - \\
\hline \multicolumn{16}{|c|}{$1530 \mathrm{G}>\mathrm{T}$} \\
\hline $\mathrm{G} / \mathrm{G}$ & 391 & $(98.0)$ & 162 & (93.6) & ref. & 271 & $(98.2)$ & 120 & $(97.6)$ & ref. & 75 & (98.7) & 316 & (97.8) & ref. \\
\hline $\mathrm{G} / \mathrm{T}$ & 7 & (1.8) & 10 & (5.8) & 0.06 & 5 & (1.8) & 2 & (1.6) & 0.72 & 1 & (1.3) & 6 & (1.9) & 0.98 \\
\hline $\mathrm{T} / \mathrm{T}$ & 1 & $(0.3)$ & 1 & (0.6) & 0.56 & 0 & $(0.0)$ & 1 & $(0.8)$ & - & 0 & $(0.0)$ & 1 & $(0.3)$ & - \\
\hline \multicolumn{16}{|c|}{$1976 \mathrm{~A}>\mathrm{G}$} \\
\hline $\mathrm{A} / \mathrm{A}$ & 386 & $(96.5)$ & 164 & $(94.8)$ & ref. & 267 & (95.7) & 119 & (98.3) & ref. & 73 & (94.8) & 313 & (96.9) & ref. \\
\hline $\mathrm{A} / \mathrm{G}$ & 14 & (3.5) & 9 & $(5.2)$ & 0.64 & 12 & (4.3) & 2 & (1.7) & 0.29 & 4 & (5.2) & 10 & (3.1) & 0.62 \\
\hline
\end{tabular}

$P$-values are calculated in a logistic regression model that did not assume any particular mode of inheritance and accounted for the presence of each genotype (0/1 and 1/1) versus the wild type genotype (0/0), adjusted for age group, sex and ethnicity (general model). For statistically significant associations, we performed a likelihood ratio tests for three different models (dominant, recessive and additive) versus the general model. The best fitting models are shown in Table 5. The numbers of individuals with assessable genotypes may differ slightly for the different SNPs

Finally, we examined the cellular mechanism of how $M$. leprae modulates TLR4-mediated immune responses. We previously demonstrated that irradiated $M$. leprae or its cell wall extracts stimulate TNF- $\alpha$ secretion through TLR2, but not TLR4, in bone marrow-derived macrophages [35]. In HEK293 cells transfected with an NF-KB luciferase construct, we also found that TLR2, but not TLR4, mediates signalling in response to stimulation with irradiated $M$. leprae or its cell wall extracts (data not shown and [35]). Together, these results suggested that M. leprae does not directly stimulate an immune response through TLR4, which is consistent with the absence of LPS in its cell wall.

We hypothesised that $M$. leprae modulates TLR4mediated immune responses by regulating shared components of the downstream TLR signalling pathway. To test this hypothesis, we isolated and stimulated human monocytes with LPS and M. leprae and measured cytokine production in culture supernatants. In contrast to LPS, $M$. leprae did not induce IL-1 $\beta$, IL-6 or IL-12p70 in monocytes (Fig. 1A, B, C). To examine whether M. leprae inhibits or merely fails to activate cytokine production, we examined cytokine production with mixed stimulations. In monocytes that were concurrently co-stimulated with $M$. leprae and LPS, cytokine production was similar to that of LPS alone. In contrast, when cells were pre-stimulated with M. leprae for 5 or $24 \mathrm{~h}$ and then stimulated with LPS, IL-
$1 \beta$ production was lower in comparison to stimulation with LPS alone (Fig. 1A). A similar trend was observed for IL-6 production after $24 \mathrm{~h}$ of $M$. leprae pre-stimulation, but the differences were not statistically significant (Fig. 1B). In contrast to IL- 6 and IL- $1 \beta$, there was no difference in IL12 p70 production among the different conditions tested (Fig. 1C). As a control, we repeated the experiment in the opposite stimulation order (LPS followed by M. leprae) and found no difference in cytokine levels. Next, we examined whether M. leprae modulated LPS-induced signalling in PBMCs. Similar to monocytes, we found that the prestimulation of PBMCs with M. leprae for $24 \mathrm{~h}$ led to decreased LPS-induced secretion of IL-6 in comparison to stimulation with LPS alone (Fig. 1E). IL- $1 \beta$ levels were also lower in the PBMCs that were pre-treated with $M$. leprae for $24 \mathrm{~h}$, although the difference was not statistically significant (Fig. 1D). Similar to monocytes, no differences in IL- 6 or IL- $1 \beta$ levels were observed when the cells were stimulated with $M$. leprae after LPS. There was no difference among the different stimulation conditions when comparing levels of IL-12p70 or several T cell cytokines (IFN- $\gamma$, IL-4 or IL-17). Together, these results suggest that M. leprae inhibits the LPS induction of IL- $1 \beta$ and IL-6 secretion from monocytes. Furthermore, this effect was selective and not found for T-cell cytokines or other monocyte cytokines, such as IL-12p70. 


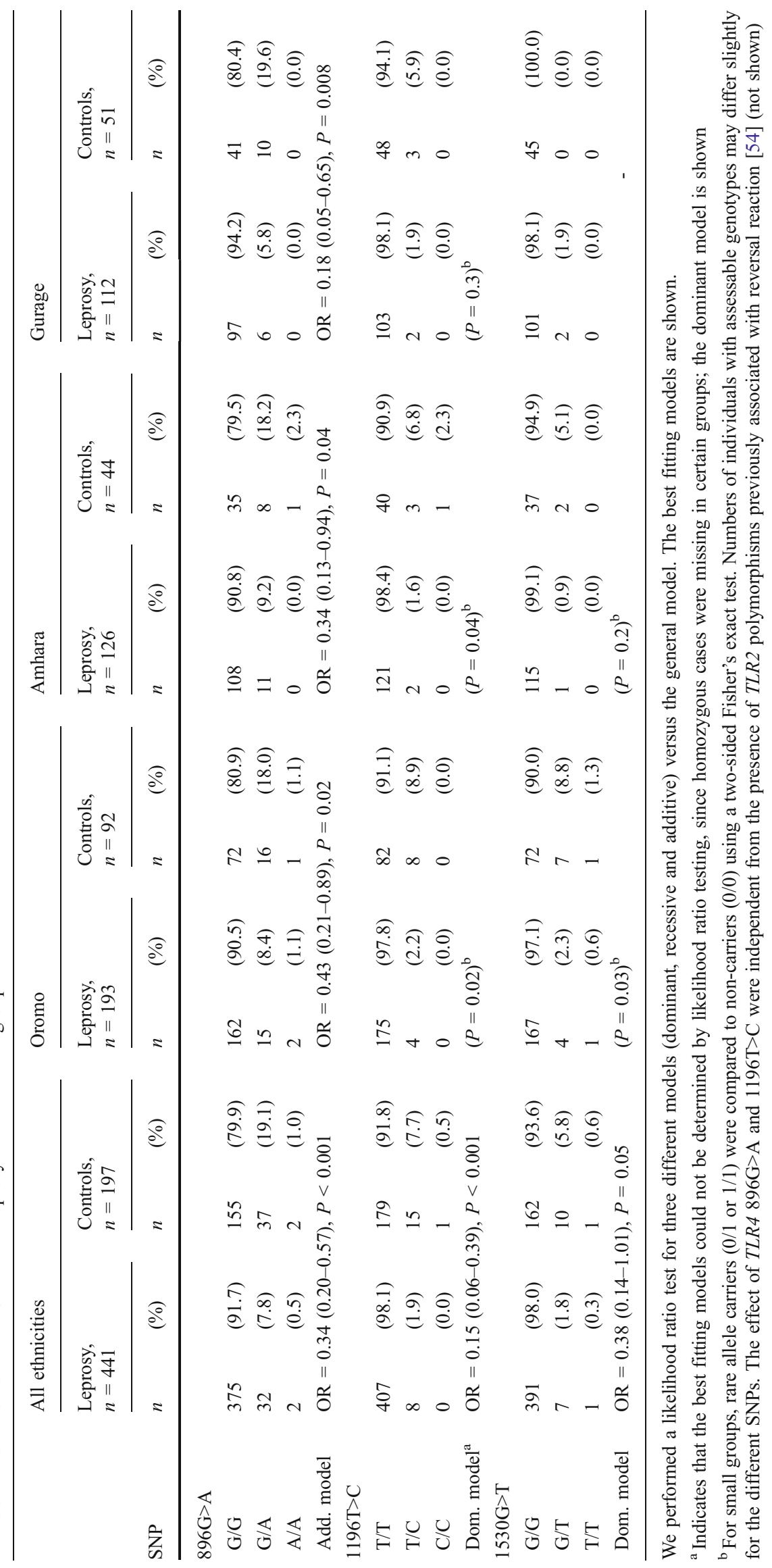


Table 6 Association of TLR4 haplotypes with leprosy

\begin{tabular}{lll}
\hline Haplotype & \multicolumn{2}{l}{ Leprosy $(n=441)$ vs. controls $(n=197)$} \\
\cline { 2 - 3 } & OR $(95 \% \mathrm{CI})$ & $P$-value $)$ \\
\hline 1) ACGA & ref. & - \\
2) GCGA & $0.48(0.21-1.08)$ & 0.08 \\
3) GTGA & $0.12(0.05-0.34)$ & $<0.001$ \\
4) ACGG & $0.62(0.23-1.67)$ & 0.3 \\
5) GCTA & $0.23(0.08-0.69)$ & 0.008
\end{tabular}

$P$-values are calculated in a logistic regression model including all haplotypes (each coded 0,1 or 2, for the presence of no, one or two copies of the haplotype), using haplotype 1 as a reference. The results are adjusted for age group, sex and ethnicity

\section{Discussion}

In this paper, we showed that two SNPs in TLR4 $(896 \mathrm{G}>\mathrm{A}$ [D299G] and 1196C $>$ T [T399I]) were associated with protection against leprosy in an Ethiopian cohort of leprosy patients and healthy controls. We also demonstrated that $M$. leprae downregulates TLR4-mediated cytokine production in monocytes.

Recent studies have also found associations of TLR SNPs and leprosy susceptibility. An SNP in TLR1 (T1805G [I602S]) was associated with $M$. leprae infection [36-38]. Another study reported that a TLR2 SNP (C2029T [R677W]) located in a critical region of the Toll-interleukin receptor (TIR) domain was associated with lepromatous leprosy in
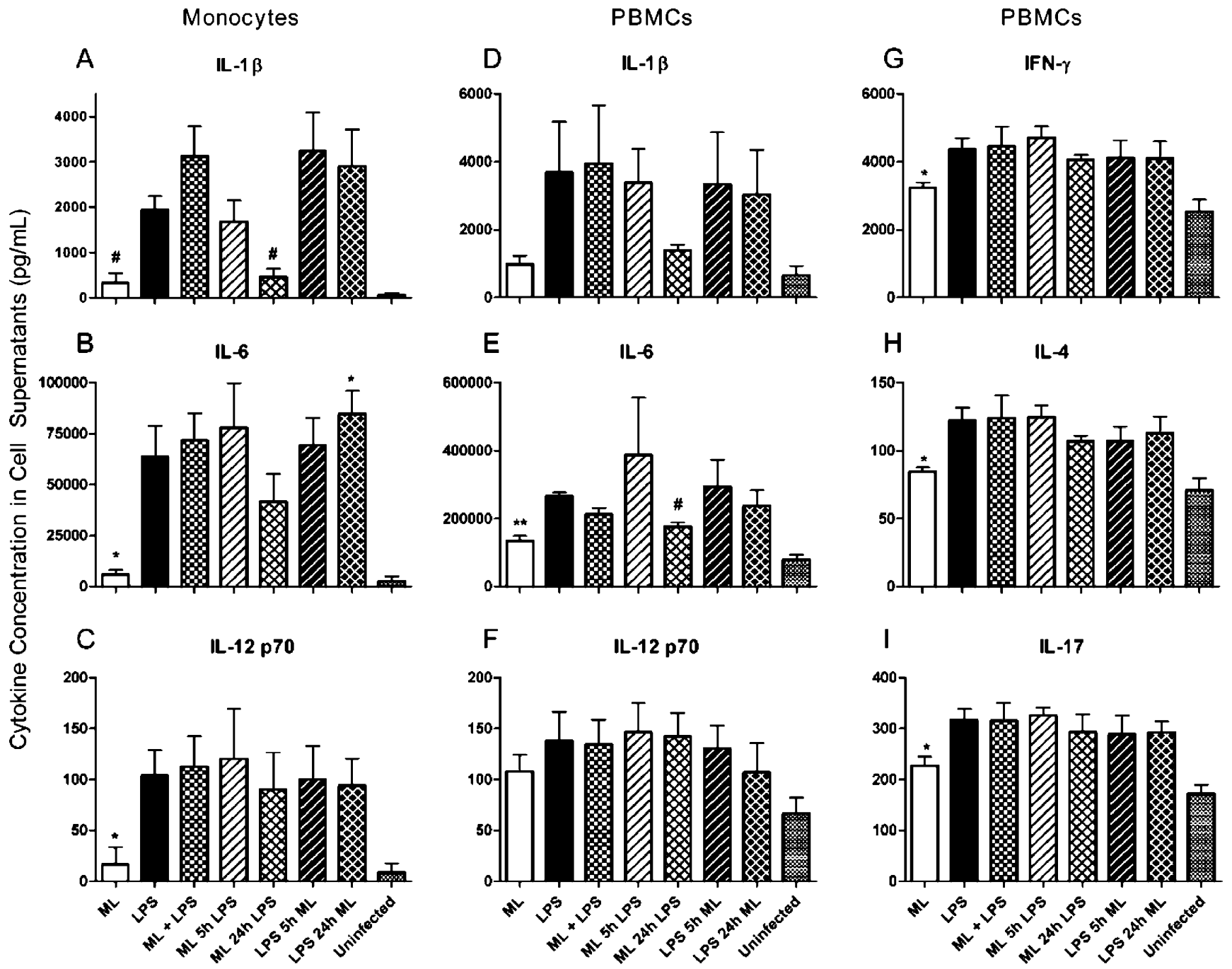

Fig. 1 Monocyte and peripheral blood mononuclear cell (PBMC) cytokine response to mixed stimulation with Mycobacterium leprae and lipopolysaccharide (LPS). Human peripheral blood monocytes and PBMCs were isolated and infected at a multiplicity of infection (MOI) of 5:1 with heat-killed M. leprae (ML), LPS (100 ng/mL), $M$. leprae and LPS simultaneously, or pre-stimulation with either $M$. leprae or LPS for 5 or $24 \mathrm{~h}$, followed by treatment with the other stimulus. Supernatants were collected at $48 \mathrm{~h}$ post-stimulation and analysed by Luminex for the presence of multiple cytokines. The results are the means \pm standard error of three experiments (donors) performed in duplicate, with the exceptions of IL-1 $\beta$ production from monocytes (five donors) and IL-6 production from monocytes (four donors). A two-tailed paired $t$-test was used for statistical analysis $\left({ }^{*} P<\right.$ $0.05, * * P<0.005, \# P<0.001$, in comparison to LPS alone) 
Korea [39]. While an amino-acid substitution at this location completely abolished TLR2 signalling in transfected cells [35], subsequent studies revealed that this supposedly functional SNP was, in fact, located in a highly homologous pseudogene region located $23 \mathrm{kB}$ upstream of the TLR2 gene [40]. More recently, we showed that a microsatellite polymorphism located in TLR2 significantly increased the risk of leprosy reversal reaction [20]. Allelic length variations in the microsatellite may influence promoter activity and modify TLR2 function through alteration of its expression level [41]. However, the TLR2 microsatellite polymorphism associated with leprosy reversal reaction did not strongly influence susceptibility to leprosy itself.

In the present study, we examined whether polymorphisms in TLR4 influenced susceptibility to or the clinical characteristics of leprosy in an Ethiopian cohort. We found that the minor alleles of two TLR4 SNPs (896G>A [D299G] and $1196 \mathrm{C}>\mathrm{T}$ [T399I]) were associated with a reduced risk of developing leprosy. Such a protective effect is in contrast with most studies. In fact, TLR4 896A and 1196T were frequently associated with increased susceptibility to pathogens, including Gram-negative bacteria, Brucella species, respiratory syncytial virus (RSV), Plasmodium falciparum and Candida albicans (reviewed in [6]).

Our data support the hypothesis that, in the case of specific infections, dysfunctional TLR SNPs may reduce, instead of increase, susceptibility to infections. This hypothesis is also supported by previous observations: the dysfunctional allele of TLR1 1805G (602S) exerted a protective effect against leprosy [37]; the dysfunctional 2258G/A (R753Q) was shown to increase the risk of tuberculosis [42] but to protect against Lyme borreliosis [43]; finally, as it is the case for leprosy, TLR4 896A and $1196 \mathrm{~T}$ were shown to protect from Legionnaire's disease [44]. The reason why a specific TLR allele exerts a protective effect against some infections and an increased risk for others is unknown. These differences reflect the complexity of human immune responses to infectious agents and may result from co-evolving selective pressures in hosts and pathogens. TLR4 896G >A and 1196C $>$ T have been intensively examined in functional and genetic epidemiological studies. 896A was associated with LPS hypo-responsiveness after the in vivo inhalation of endotoxin [23, 45]. In vitro cellular investigations also suggested that 299G and/or 399I was unable to mediate LPS signalling in some [23, 46] but not all cell types [47-49]. These seemingly contradictory findings may be explained by the use of small sample sizes, which resulted in differences with borderline statistical significance; comparison of different cell types; use of different doses and types of LPS; and measurement of different cytokines and inflammatory markers. Taken together, these studies suggest that SNPs $896 \mathrm{G}>\mathrm{A}$ and $1196 \mathrm{C}>\mathrm{T}$ partially influence inflammatory pathways under some experimental conditions.
While TLR2 has been clearly implicated in the innate immune response to $M$. leprae, the role of TLR 4 is currently unknown. We previously found that irradiated M. leprae or its cell wall extracts stimulated TNF- $\alpha$ production through TLR2, but not TLR4 [35]. If live $M$. tuberculosis signals through TLR4, then it is plausible that M. leprae may do so similarly [13]. Alternatively, TLR4 may modulate inflammatory processes that influence leprosy disease manifestations but are not attributable to direct stimulation by $M$. leprae. Consistent with this hypothesis, we found that the stimulation of monocytes with $M$. leprae inhibited their subsequent response to TLR4 stimulation with LPS. There are several possible mechanisms of this inhibitory effect, including tolerance, a well-described phenomenon where prior exposure of cells to TLR ligands results in a transient hypo-responsive state that is refractory to additional stimulation [50]. Several mechanisms have been proposed for tolerance, including the alteration of expression levels of negative and positive regulators of the TLR signalling pathway. For example, IRAK-M is a negative regulator of the TLR signalling pathway that is downstream of both TLR2 and TLR4 and is involved in endotoxin tolerance [51]. M. leprae may alter the expression of molecules such as IRAK-M through TLR2 stimulation and, ultimately, modulate LPS/TLR4 responsiveness through such a shared signalling intermediate. An alternative mechanism could be from direct inhibitory effects of an $M$. leprae molecule on the TLR signalling pathway. There are several precedents for this mechanism, including YopJ inhibition of MAPK signalling by Yersinia pestis [52] and the recently described TIR domain containing proteins (Tcps) in Escherichia coli that bind MyD88 and inhibit TLR-induced signalling pathways [53]. Future studies will address these possible mechanisms of $M$. leprae inhibition of TLR4 signalling. The alteration of monocyte responses to M. leprae by TLR4 polymorphisms via these different mechanisms could modulate the growth of bacilli, the nature and degree of the innate immune response, and the subsequent adaptive immune response. TLRs are known to influence Th1-Th2 pathway development in mice and such immunomodulatory effects could operate in humans as well [7]. TLR4 polymorphisms may modulate several of these immunologic effects and, thereby, influence overall susceptibility to leprosy. Future studies will address which cellular immune responses are modulated by TLR 4 polymorphisms

This study was limited by the low frequency of the minor alleles of TLR4. This issue was of particular concern for the analyses of leprosy types (lepromatous versus tuberculoid), as well as for leprosy complications, for which it prevented stratification into separate ethnic groups and the use of multivariable models. However, the analyses of susceptibility to leprosy itself were performed in larger sample sizes. In this case, initial analyses were performed 
for the whole population, including the three major ethnic groups. In order to limit the risk of population stratification, we also performed the analyses in the three different groups separately. Overall, most observations were consistent among the three different ethnic groups.

In summary, our data show that polymorphisms in TLR4 are associated with susceptibility to leprosy in Ethiopian patients. It suggests that polymorphisms in individual TLRs may influence different clinical manifestations of the disease.

Acknowledgements This work was supported by grants from the Swiss National Science Foundation (81LA-65462 to PYB), the Swiss Foundation for Medical-Biological Grants (1121 to PYB), the Leenaards Foundation (to PYB) and the National Institute of Health (AI25032 to AA, AI22616 and AI 54361 to GK). The AMFES project in Ethiopia was funded by the International Federation of AntiLeprosy Associations (ILEP) Members through Netherlands Leprosy Relief (NLR). We thank Sarah $\mathrm{Li}$ for technical assistance with genotyping and Abraham Aseffa for his help and advice in bringing the manuscript to press.

The authors have no conflict of interest in the present manuscript.

\section{References}

1. [No authors listed] (2007) Global leprosy situation, 2007. Wkly Epidemiol Rec 82:225-232

2. Ridley DS, Jopling WH (1966) Classification of leprosy according to immunity. A five-group system. Int J Lepr Other Mycobact Dis 34:255-273

3. Scollard DM, Adams LB, Gillis TP et al (2006) The continuing challenges of leprosy. Clin Microbiol Rev 19:338-381. doi:10.1128/ CMR.19.2.338-381.2006

4. Yamamura M, Uyemura K, Deans RJ et al (1991) Defining protective responses to pathogens: cytokine profiles in leprosy lesions. Science 254:277-279. doi:10.1126/science.1925582

5. Salgame P, Abrams JS, Clayberger C et al (1991) Differing lymphokine profiles of functional subsets of human CD4 and CD8 T cell clones. Science 254:279-282. doi:10.1126/science.1681588

6. Bochud PY, Bochud M, Telenti A et al (2007) Innate immunogenetics: a tool for exploring new frontiers of host defence. Lancet Infect Dis 7:531-542. doi:10.1016/S1473-3099(07)70185-8

7. Iwasaki A, Medzhitov R (2004) Toll-like receptor control of the adaptive immune responses. Nat Immunol 5:987-995. doi:10.1038/ ni1112

8. Akira S, Uematsu S, Takeuchi O (2006) Pathogen recognition and innate immunity. Cell 124:783-801. doi:10.1016/j.cell.2006.02.015

9. Quesniaux V, Fremond C, Jacobs M et al (2004) Toll-like receptor pathways in the immune responses to mycobacteria. Microbes Infect 6:946-959. doi:10.1016/j.micinf.2004.04.016

10. Jo EK, Yang CS, Choi $\mathrm{CH}$ et al (2007) Intracellular signalling cascades regulating innate immune responses to Mycobacteria: branching out from Toll-like receptors. Cell Microbiol 9:10871098. doi:10.1111/j.1462-5822.2007.00914.x

11. Heldwein KA, Fenton MJ (2002) The role of Toll-like receptors in immunity against mycobacterial infection. Microbes Infect 4:937944. doi:10.1016/S1286-4579(02)01611-8

12. Krutzik SR, Ochoa MT, Sieling PA et al (2003) Activation and regulation of Toll-like receptors 2 and 1 in human leprosy. Nat Med 9:525-532. doi:10.1038/nm864

13. Means TK, Wang S, Lien E et al (1999) Human toll-like receptors mediate cellular activation by Mycobacterium tuberculosis. J Immunol 163:3920-3927
14. Alcaïs A, Mira M, Casanova JL et al (2005) Genetic dissection of immunity in leprosy. Curr Opin Immunol 17:44-48. doi:10.1016/ j.coi.2004.11.006

15. Alcaïs A, Alter A, Antoni G et al (2007) Stepwise replication identifies a low-producing lymphotoxin-alpha allele as a major risk factor for early-onset leprosy. Nat Genet 39:517-522. doi:10.1038/ng2000

16. Santos AR, Suffys PN, Vanderborght PR et al (2002) Role of tumor necrosis factor-alpha and interleukin-10 promoter gene polymorphisms in leprosy. J Infect Dis 186:1687-1691. doi:10.1086/345366

17. Moraes MO, Pacheco AG, Schonkeren JJ et al (2004) Interleukin10 promoter single-nucleotide polymorphisms as markers for disease susceptibility and disease severity in leprosy. Genes Immun 5:592-595. doi:10.1038/sj.gene.6364122

18. Mira MT (2006) Genetic host resistance and susceptibility to leprosy. Microbes Infect 8:1124-1131. doi:10.1016/j.micinf.2005.10.024

19. Misch EA, Hawn TR (2008) Toll-like receptor polymorphisms and susceptibility to human disease. Clin Sci (Lond) 114:347360. doi:10.1042/CS20070214

20. Bochud PY, Hawn TR, Siddiqui MR et al (2008) Toll-like receptor 2 (TLR2) polymorphisms are associated with reversal reaction in leprosy. J Infect Dis 197:253-261. doi:10.1086/524688

21. Ferwerda B, Kibiki GS, Netea MG et al (2007) The toll-like receptor 4 Asp299Gly variant and tuberculosis susceptibility in HIV-infected patients in Tanzania. AIDS 21:1375-1377. doi:10.1097/QAD.0b013e32814e6b2d

22. Bochud PY, Chien JW, Marr KA et al (2008) Toll-like receptor 4 polymorphisms and aspergillosis in stem-cell transplantation. $\mathrm{N}$ Engl J Med 359:1766-1777. doi:10.1056/NEJMoa0802629

23. Arbour NC, Lorenz E, Schutte BC et al (2000) TLR4 mutations are associated with endotoxin hyporesponsiveness in humans. Nat Genet 25:187-191. doi:10.1038/76048

24. Saunderson P, Gebre S, Desta K et al (2000) The ALERT MDT Field Evaluation Study (AMFES): a descriptive study of leprosy in Ethiopia. Patients, methods and baseline characteristics. Lepr Rev 71:273-284

25. Jopling WH (1981) A practical classification of leprosy for field workers. Lepr Rev 52:273

26. Saunderson P, Gebre S, Byass P (2000) Reversal reactions in the skin lesions of AMFES patients: incidence and risk factors. Lepr Rev 71:309-317

27. Gordon D, Abajian C, Green P (1998) Consed: a graphical tool for sequence finishing. Genome Res 8:195-202

28. Hawn TR, Dunstan SJ, Thwaites GE et al (2006) A polymorphism in Toll-interleukin 1 receptor domain containing adaptor protein is associated with susceptibility to meningeal tuberculosis. J Infect Dis 194:1127-1134. doi:10.1086/507907

29. Turvey SE, Hawn TR (2006) Towards subtlety: understanding the role of Toll-like receptor signaling in susceptibility to human infections. Clin Immunol 120:1-9. doi:10.1016/j.clim.2006.02.003

30. S.A.G.E. Statistical Analysis for Genetic Epidemiology. Case Western Reserve University. 5.0 edn, 2005

31. Lahiri R, Randhawa B, Krahenbuhl J (2005) Application of a viability-staining method for Mycobacterium leprae derived from the athymic (nu/nu) mouse foot pad. J Med Microbiol 54:235242. doi:10.1099/jmm.0.45700-0

32. Suzuki K, Fukutomi Y, Matsuoka M et al (1993) Differential production of interleukin 1 (IL-1), IL-6, tumor necrosis factor, and IL-1 receptor antagonist by human monocytes stimulated with Mycobacterium leprae and M. bovis BCG. Int J Lepr Other Mycobact Dis 61:609-618

33. Murray RA, Siddiqui MR, Mendillo M et al (2007) Mycobacterium leprae inhibits dendritic cell activation and maturation. $\mathrm{J}$ Immunol 178:338-344

34. Ferwerda B, McCall MB, Alonso S et al (2007) TLR4 polymorphisms, infectious diseases, and evolutionary pressure during 
migration of modern humans. Proc Natl Acad Sci USA 104:16645-16650. doi:10.1073/pnas.0704828104

35. Bochud PY, Hawn TR, Aderem A (2003) Cutting edge: a Toll-like receptor 2 polymorphism that is associated with lepromatous leprosy is unable to mediate mycobacterial signaling. J Immunol 170:3451-3454

36. Misch EA, Macdonald M, Ranjit C et al (2008) Human TLR1 deficiency is associated with impaired mycobacterial signaling and protection from leprosy reversal reaction. PLoS Negl Trop Dis 2:e231. doi:10.1371/journal.pntd.0000231

37. Johnson CM, Lyle EA, Omueti KO et al (2007) Cutting edge: A common polymorphism impairs cell surface trafficking and functional responses of TLR1 but protects against leprosy. J Immunol 178:7520-7524

38. Hawn TR, Misch EA, Dunstan SJ et al (2007) A common human TLR1 polymorphism regulates the innate immune response to lipopeptides. Eur J Immunol 37:2280-2289

39. Kang TJ, Chae GT (2001) Detection of Toll-like receptor 2 (TLR2) mutation in the lepromatous leprosy patients. FEMS Immunol Med Microbiol 31:53-58. doi:10.1111/j.1574-695X.2001.tb01586.x

40. Malhotra D, Relhan V, Reddy BS et al (2005) TLR2 Arg677Trp polymorphism in leprosy: revisited. Hum Genet 116:413-415. doi:10.1007/s00439-004-1249-9

41. Yim JJ, Ding L, Schäffer AA et al (2004) A microsatellite polymorphism in intron 2 of human Toll-like receptor 2 gene: functional implications and racial differences. FEMS Immunol Med Microbiol 40:163-169. doi:10.1016/S0928-8244(03)00342-0

42. Ogus AC, Yoldas B, Ozdemir T et al (2004) The Arg753GLn polymorphism of the human toll-like receptor 2 gene in tuberculosis disease. Eur Respir J 23:219-223. doi:10.1183/ 09031936.03.00061703

43. Schröder NW, Diterich I, Zinke A et al (2005) Heterozygous Arg753Gln polymorphism of human TLR-2 impairs immune activation by Borrelia burgdorferi and protects from late stage Lyme disease. J Immunol 175:2534-2540

44. Hawn TR, Verbon A, Janer M et al (2005) Toll-like receptor 4 polymorphisms are associated with resistance to Legionnaires' disease. Proc Natl Acad Sci USA 102:2487-2489. doi:10.1073/ pnas. 0409831102
45. Michel O, LeVan TD, Stern D et al (2003) Systemic responsiveness to lipopolysaccharide and polymorphisms in the toll-like receptor 4 gene in human beings. J Allergy Clin Immunol 112:923-929. doi:10.1016/j.jaci.2003.05.001

46. Fagerås Böttcher $\mathrm{M}$, Hmani-Aifa $\mathrm{M}$, Lindström A et al (2004) A TLR4 polymorphism is associated with asthma and reduced lipopolysaccharide-induced interleukin-12(p70) responses in Swedish children. J Allergy Clin Immunol 114:561-567. doi:10.1016/j.jaci.2004.04.050

47. Erridge C, Stewart J, Poxton IR (2003) Monocytes heterozygous for the Asp299Gly and Thr399Ile mutations in the Toll-like receptor 4 gene show no deficit in lipopolysaccharide signalling. $\mathrm{J}$ Exp Med 197:1787-1791. doi:10.1084/jem.20022078

48. von Aulock S, Schröder NW, Gueinzius K et al (2003) Heterozygous toll-like receptor 4 polymorphism does not influence lipopolysaccharide-induced cytokine release in human whole blood. J Infect Dis 188:938-943. doi:10.1086/378095

49. Paulus SC, Hirschfeld AF, Victor RE et al (2007) Common human Toll-like receptor 4 polymorphisms - role in susceptibility to respiratory syncytial virus infection and functional immunological relevance. Clin Immunol 123:252-277

50. Medvedev AE, Sabroe I, Hasday JD et al (2006) Tolerance to microbial TLR ligands: molecular mechanisms and relevance to disease. J Endotoxin Res 12:133-150. doi:10.1179/096805106X102255

51. Kobayashi K, Hernandez LD, Galán JE et al (2002) IRAK-M is a negative regulator of Toll-like receptor signaling. Cell 110:191202. doi:10.1016/S0092-8674(02)00827-9

52. Viboud GI, Bliska JB (2005) Yersinia outer proteins: role in modulation of host cell signaling responses and pathogenesis. Annu Rev Microbiol 59:69-89. doi:10.1146/annurev.micro.59. 030804.121320

53. Cirl C, Wieser A, Yadav M et al (2008) Subversion of Toll-like receptor signaling by a unique family of bacterial Toll/interleukin1 receptor domain-containing proteins. Nat Med 14:399-406. doi:10.1038/nm1734

54. Bochud PY, Hawn TR, Siddiqui MR et al (2008) Toll-like receptor 2 (TLR2) polymorphisms are associated with reversal reaction in leprosy. J Infect Dis 197:253-261. doi:10.1086/ 524688 